\title{
From the Archives of Asian History
}

\author{
Dear Readers,
}

This issue marks the creation of a new section within JESHO entitled 'From the Archives of Asian History.' This section will feature seminal works in the history of Asia from the late Antique period to the 2oth century, which were originally published in languages other than English, but which unfortunately have long been forgotten and therefore tend to be underappreciated, especially by a younger generation of scholars. There are many ways to explain the peculiar phenomenon of ground-breaking scholarship falling into desuetude; but it is ironic to observe that, while major digitization projects have been now underway for a decade or more, thereby impressing upon many the idea that everything is available on-line, academic conformism remains rampant, indeed unrestrained. Time and again must JESHO's editors and readers alike lament how manuscripts submitted for consideration tend to reproduce often uncritically the prevailing current of thought, to privilege established views over works that today are less cited, and disregard earlier scholarship that in fact contributed significantly to the advancement of historiography. While modern scholarship takes pride in the global reach of its perspectives and analyses, and almost every social science discipline reinvents itself by adding the adjective 'global' to its conventional name, the scholars who practice in these disciplines increasingly rely almost exclusively on anglophone literature. At the same time, we all must take stock of enduring asymmetries between national systems of higher education, which fuel a general mistrust for scholarship produced in countries outside the Anglo-Saxon world. It is an unfortunate fact that a graduate student coming from the Global South seeking to secure funding in Europe or North America will need not just to demonstrate her originality, but also her commitment to engaging with scholarship published in English rather than in, say, Portuguese or Turkish. Finally, we should all pause to reflect on the disincentive effects on multilingualism originating from the sinking quality of public education. Until the 199os, for an undergraduate to hone multiple linguistic skills was a prerequisite for admission into schools offering courses on the histories and literatures of Asia. Nowadays, by contrast, lecturers are expected to constrain their syllabi mainly to scholarship 
published in English. Let us not be too discouraged, however, by this baleful present state of affairs: JESHO will offer an opportunity to rediscover today less-known reference works in the various disciplines and subfields that fall within the umbrella of 'Asian History'. Also, each and every article featured in this section will be accompanied by a reflection essay providing ample commentary on its historiographical significance and on its potential relevance for the pursuit of new intellectual explorations. In this endeavour our aim is not to initiate a new translation movement, the likes of which changed the course of history in the past, but rather to encourage scholars to incorporate literature available in languages other than English in their studies, either through translations or by reading relevant articles and books in the original.

\section{Paolo Sartori}

